\title{
Challenges and Countermeasures Faced by the Local Governments under the New Environmental Law in China
}

\author{
Yichao Yuan ${ }^{1}$, Kuiran Shi ${ }^{2}$ and Zhaowen Kang ${ }^{1}$ \\ ${ }^{1}$ Nanjing Tech University, Nanjing, 211800 \\ ${ }^{2}$ Nanjing Audit University, Nanjing, 211815
}

\begin{abstract}
The New Environmental Protection Laws in China have taken effect on Jan 1, 2015, which is an important milestone in the history of environmental protection legislation. Also, the game relationship between governments' supervision and firms' pollution treatment is re-examine by the academic circles. In accordance with the latest environmental policy, this paper studies the interaction between governments and firms under the setting of daily penalty by applying evolutionary game theory. Specifically, with the daily penalty amount being viewed as an critical parameter, evolutionarily stable strategies under different situations of amount of penalty are investigated. The results show that daily penalty is the key factor influencing evolutionary stable strategies, daily penalty would be helpful for the system to evolve to the direction in which firms controlling pollution consciously and the governments reducing the proportion of regulation quickly and effectively. Thus, the society can cultivate the right orientation under which the cost of governments' regulation can be reduced and advocating lawabiding culture can be formed.
\end{abstract}

Keywords-daily penalty; government regulation; evolutionary game; evolutionary stable strategy

\section{INTRODUCTION}

The implementation of the new environmental protection laws in China has intensified the penalties for environmental violations. Which is known as the "sword" clause, the daily penalty, is not a fine for once, but to make a settlement before and after the reorganization. In fact, the root of environmental pollution is the contradiction between people yearn for beautiful environment and firms to pursue profit maximization. Game theory provides an effective tool for such problems. ZHANG Xue-gang and ZHONG Mao-chu ${ }^{[1]}$ pointed out that reducing government benefits for firm pollution and reducing the cost of government supervision, increasing the firms pollution penalty are conducive to the improvement of environmental quality. ZHAO Lai-jun ${ }^{[2]}$ has studied the coordination problem of water pollution transfer tax and obtained the equilibrium solution by the ideal point method.

A review of the existing results is not difficult to see that studies mostly focused on the government's necessity for firms' regulation, supervision mechanism, countermeasures and suggestions etc. There are few papers have considered the limited rationality of participants, especially the discussion from the perspective of evolution of the interaction between the governments and firms. Foulon $\mathrm{J}$ etal ${ }^{[3]}$ have analyzed the role governments played in the regulation of the firms, and pointed out that the governments' regulation for firms have the deterrent effect in a certain extent. Damania $\mathrm{R}^{[4]}$ applied the repeated game method to discuss the role of the governments in the regulation of firms. In this case, JIA Jingquan etal ${ }^{[5]}$ constructs the evolution model to analyze the strategy choice of the governments and the firms.

Obviously, in order to implement the new "environmental protection law" effectively, governments at all levels should be responsible for the environmental quality of their administrative areas. The new "environmental protection law" in China emphasized the role of local government clearly and urged the governments to cut off dependence on the firms consciously. In this context, how can the two groups of limited rationality, governments and firms, adjust their strategic behavior dynamically? This paper regards environmental quality supervision as a dynamic process of gradual learning by using evolutionary game method, and explores the key elements of the governments and firms behavior choices combined with the latest environmental policy.

\section{MOdEL BuILDING}

Taking into account the evolutionary game between the firms and the governments. For profit maximization, there are two measures for sewage treatment of firms: 1) Discharge after reaching standard;(2) direct discharge. Its action space is (treatment, no treatment). The action space of governments is (regulation, no regulation). Drawing on the research methods of the literature ${ }^{[6]}$, the basic assumptions of the model are as follows:

Hypothesis 1: In the firms groups, the ratio of the decision to treat is $x$, the proportion of the decision not to treat is 1- $x$. In the governments groups, the proportion of adopting the supervision strategy is $y$, and the proportion of the non supervision strategy is 1-y. Firm groups and government groups are limited rationality, and the two can not make the best choice in a decision, and need long-term cooperation to make adjustments.

Hypothesis 2: The cost of water treatment of firms is $C_{t 1}$, such as: firms investment including water treatment equipment technology and equipment cost of raw materials, transportation cost of raw materials, labor costs. The cost that 
firms do not deal with the sewage is $C_{t 2}$, such as do not buy water treatment equipments, do not recruit professional personnel. Obviously, $C_{t 1}>C_{t 2}$. Regardless of whether the firms to deal with the sewage, the governments subsidy for environmental protection firms cost is D.

Hypothesis 3: The cost of governments regulation is $C_{g}$,including the governments' payment expenses for purchasing of services from the third party and Personnel wages. Governments regulatory incentives (the central government has incorporated environmental quality into the government's performance assessment) is $S_{g}$,the government's payoff is $S_{g}-C_{g}-D$.

Hypothesis 4: If the governments find the firms not acting, the fine received by the firms is $f(t)=a t$. This is according to the new environmental protection laws and regulations for the daily punishment, firms' loss is greater than the cost of dealing with the sewage: $f(t)>C_{t 1}$. There is a certain probability $\beta$ that the firms can be found not treat the sewage and the punished cost of governments is $f_{g}$.

TABLE I. PAYOFF MATRIX OF THE GOVERNMENT-FIRM GAME

\begin{tabular}{c|c|l|l}
\hline \multicolumn{2}{c|}{} & \multicolumn{2}{c}{ Governments } \\
\cline { 3 - 4 } \multicolumn{2}{c|}{} & \multicolumn{1}{c}{ regulation $y$} & $\begin{array}{l}\text { Non regulation 1- } \\
y\end{array}$ \\
\hline \multirow{4}{*}{ Firms } & $\begin{array}{l}\text { treatment } \\
x\end{array}$ & $\begin{array}{l}D-C_{t 1} \\
S_{g}-C_{g}-D\end{array}$ & $D-C_{t 1},-D$ \\
\cline { 2 - 4 } & No & $D-C_{t 2}-f(t)$, & $D-C_{t 2}-\beta f(t)$ \\
& treatment \\
& $1-x$ & $S_{g}-C_{g}-D$ & $-\beta f_{g}-D$ \\
\hline
\end{tabular}

According to the above hypotheses, the payoff matrix of the game between the governments and the firms is established, as shown in table 1.

\section{EVOLUTIONARY GAME MODEL ANALYSIS}

\section{A. The Balance Points of Evolution Process}

For firms, the average expected payoff:

$$
\bar{U}_{1}=x U_{1 d}+(1-x) U_{1 n}
$$

For governments, the average expected payoff:

$$
\bar{U}_{2}=y U_{2 d}+(1-y) U_{2 n}
$$

According to the related theory of evolutionary game we can get the replicated dynamic equation as follows

$$
\begin{aligned}
& \dot{x}=x(1-x)\left[-C_{t 1}+C_{t 2}+y f(t)+\beta f(t)-y \beta f(t)\right] \\
& \dot{y}=y(1-y)\left(S_{g}-C_{g}+\beta f_{g}-x \beta f_{g}\right)
\end{aligned}
$$

A two-dimensional dynamic system (J) can be obtained by differential equations (3) and (4)

$$
\left\{\begin{array}{l}
\frac{d x}{d t}=x(1-x)\left[-C_{t 1}+C_{t 2}+\beta f(t)+(1-\beta) y f(t)\right] \\
\frac{d y}{d t}=y(1-y)\left(S_{g}-C_{g}+\beta f_{g}-x \beta f_{g}\right)
\end{array}\right.
$$

For systems (J), we can obtain the following conclusions by $\frac{d x}{d t}=0$ and $\frac{d y}{d t}=0$.

Proposition 1:Dynamic system $(\mathrm{J})$ has five equilibria, namely $(0,0),(0,1),(1,0),(1,1)$ and $\left(x_{M}, y_{M}\right) \cdot x_{M}=\frac{S_{g}-C_{g}+\beta f_{g}}{\beta f_{g}}$, $y_{M}=\frac{-C_{t 1}+C_{t 2}+\beta f(t)}{(\beta-1) f(t)}$.

\section{B. Stability Analysis of Equilibrium}

According to Friedman ${ }^{[7]}$, a method for judging the stability of dynamic systems is proposed. The resulting Jaconbian matrix is

$$
\begin{aligned}
& J=\left[\begin{array}{ll}
\frac{\partial \dot{x}}{\partial x} & \frac{\partial \dot{x}}{\partial y} \\
\frac{\partial \dot{y}}{\partial x} & \frac{\partial \dot{y}}{\partial y}
\end{array}\right]=\left[\begin{array}{ll}
a_{11} & a_{12} \\
a_{21} & a_{22}
\end{array}\right] . \\
& a_{11}=(1-2 x)\left[-C_{t 1}+C_{t 2}+\beta f(t)+(1-\beta) y a t\right], \\
& a_{12}=x(1-x)(1-\beta) a t, a_{21}=-y(1-y) \beta f_{g}, \\
& a_{22}=(1-2 y)\left(S_{g}-C_{g}+\beta f_{g}-x \beta f_{g}\right) .
\end{aligned}
$$

For simplicity, the specific values of the above Local equilibrium points have been calculated, as shown in Table 2 below.

TABLE II. RESULTS FOR DIFFERENT FIXED POINTS

\begin{tabular}{lllll}
\hline Equilibrium & $a_{11}$ & $a_{12}$ & $a_{21}$ & $a_{22}$ \\
\hline$(0,0)$ & $-C_{t 1}+C_{t 2}+\beta a t$ & 0 & 0 & $S_{g}-C_{g}+\beta f_{g}$ \\
& & & & \\
$(0,1)$ & $-C_{t 1}+C_{t 2}+a t$ & 0 & 0 & $-S_{g}+C_{g}-\beta f_{g}$ \\
$(1,0)$ & $C_{t 1}-C_{t 2}-\beta a t$ & 0 & 0 & $S_{g}-C_{g}$ \\
$(1,1)$ & $C_{t 1}-C_{t 2}-a t$ & 0 & 0 & $-S_{g}+C_{g}$ \\
$\left(\mathrm{x}_{\mathrm{M}}, \mathrm{y}_{\mathrm{M}}\right)$ & 0 & A & B & 0 \\
\hline
\end{tabular}

$$
\begin{aligned}
& A=\frac{S_{g}-C_{g}+\beta f_{g}}{\beta f_{g}}\left(1-\frac{S_{g}-C_{g}+\beta f_{g}}{\beta f_{g}}\right)(1-\beta) f(t) \\
& B=\frac{-C_{t 1}+C_{t 2}+\beta f(t)}{(\beta-1) y f(t)}\left[\frac{-C_{t 1}+C_{t 2}+\beta f(t)}{(\beta-1) y f(t)}-1\right] \beta f_{g}
\end{aligned}
$$


As shown in Table 2, the local equilibrium ( $\mathrm{x}_{\mathrm{M}}, \mathrm{y}_{\mathrm{M}}$ ) dissatisfy with the trace condition.

Proposition 2: (1) When $C_{t 1}-C_{t 2}<a t<\frac{C_{11}-C_{12}}{\beta}$ and $S_{g}-C_{g}+\beta f_{g}<0$ or when $a t<C_{t 1}-C_{t 2}$ and $S_{g}-C_{g}+\beta f_{g}<0$, the ESS of the system $(\mathrm{J})$ is $(0,0)$;

(2) when $C_{\mathrm{t} 1}-C_{\mathrm{t} 2}<a t<\frac{C_{\mathrm{t} 1}-C_{\mathrm{t} 2}}{\beta} \quad$ and $\quad C_{g}<S_{g} \quad$ or when $\beta a t>C_{t 1}-C_{t 2}$ and $C_{g}<S_{g}$, the ESS of the system (J) is $(1,1)$.

Proof: The following is the proof of conclusions (1). Conclusions (2) can be obtained by the same way. For dynamic systems (J), two cases can be obtained by calculating the Jaconbian matrix. Similarly, the following propositions 3 and 4 can be obtained.

TABLE III. EVOLUTIONARY STABILITY OF FIXED POINTS FOR $S_{g}>C_{g}$ AND $\beta a t>C_{t 1}-C_{t 2}$

\begin{tabular}{clll}
\hline Equilibrium point & trJ & detJ & stability \\
\hline$(0,0)$ & - & + & ESS \\
$(0,1)$ & + & + & Unstable point \\
$(1,0)$ & Uncertain & - & saddle point \\
$(1,1)$ & Uncertain & - & saddle point \\
\hline
\end{tabular}

TABLE IV. EVOLUTIONARY STABILITY OF FIXED POINTS FOR $a t<C_{t 1}-C_{t 2}$ AND $S_{g}-C_{g}+\beta f_{g}<0$

\begin{tabular}{clll}
\hline Equilibrium point & trJ & detJ & stability \\
& & & \\
\hline$(0,0)$ & - & + & ESS \\
$(0,1)$ & Uncertain & - & saddle point \\
$(1,0)$ & Uncertain & - & saddle point \\
$(1,1)$ & + & + & Unstable point \\
\hline
\end{tabular}

Proposition 3:(1) when $a t<C_{t 1}-C_{t 2}$ and $C_{g}-\beta f_{g}<S_{g}<C_{g}$ or when $a t<C_{t 1}-C_{t 2}$ and $S_{g}>C_{g}$, the ESS of the system $(J)$ is $(0,1)$;

(2) when $\beta a t>C_{t 1}-C_{t 2}$ and $S_{g}-C_{g}+\beta f_{g}<0$, or when $\beta a t>C_{t 1}-C_{t 2}$ and $C_{g}-\beta f_{g}<S_{g}<C_{g}$, the ESS of the system (J) is $(1,0)$.

Proposition 4: when $C_{t 1}-C_{t 2}<a t<\frac{C_{t 1}-C_{t 2}}{\beta} \quad$ and $C_{g}-\beta f_{g}<S_{g}<C_{g}$, the system (J) does not exist ESS.

\section{CONCLUSION}

Under the background of the implementation of the new "environmental protection law" in China, this paper gives full consideration to the behavior games between the governments and the firms, the evolutionary stability strategies are obtained under different conditions. This paper has clarified the government regulatory incentives, supervision cost, the strength of daily penalty are key factors to influence the evolution game behavior of governments and firms. The research conclusions of this paper has some enlightenment: The governments can urge firms to deal with sewage consciously by controlling the relevant parameters. For example, when the penalty received by firms greater than the cost gap between treatment and no-treatment, firms treat with the sewage consciously by taking into account the serious punishment of the daily penalty. Governments can reduce regulatory costs and put more energy into other social services. The effectiveness of the new environmental laws are reflected from the positive perspective.

Further research can examine the government's different level of regulation. There are also interesting questions about the Cournot and Stackelberg game between the environmental protection firms in oligopoly.

\section{ACKNOWLEDGMENT}

This work was supported by National Natural Science Foundation of China (Grant No. 71301073), the National Social Science Foundation of China (Grant No. 16FGL011), Jiangsu provincial key disciplines of Applied Economics (Grant No. Su Zhengban Series No. [2014]37)and Postgraduate Practical Innovation Program in JiangSu(SJCX17_0302).

\section{REFERENCES}

[1] ZHANG Xue-gang, ZHONG Mao-chu. Research about Government Regulation and the Firm Environment Pollution under Perspective of Game Theory [J]. China Population, Resources and Environment, 2011; 21(2):31-35.

[2] ZHAO Lai-jun. Harmonizing model with transfer tax on the transboundary pollution of lake basin[J]. System Engineering-Theory and Practice, 2011; 31(2): 364-370.

[3] Foulon J, Lanoie P, Laplante B. Incentives for pollution control:regulation or information?[J]. Journal of Environmental Economics and Management, 2002, 44(1): 169-187.

[4] Damania R. Environmental regulation and financial structure in an oligopoly supergame[J]. Environmental Modelling \& Software, 2001,16(2): 119-129.

[5] JIA Jing-quan, BU Hua YAO Sheng. A Study of Environmental Information Disclosure Supervision Based on Evolutionary Game[J]. East China Economic Management, 2014; 28(5): 145-148.

[6] YU Tao, LIU Chang-yu. The Analysis of Evolution Game Model and Simulation between Governments and the Third-Party in Product Quality Regulation[J]. Chinese Journal of Management Science, 2016; 24(6): 91-96.

[7] Friedman D. Evolutionary game in economics [J]. Econometrica, 1991, 59(3): 637-666. 